\title{
Family therapy improved outcomes in patients with early onset and short history anorexia nervosa
}

\author{
Eisler I, Dare C, Russell GFM, et al. Family and individual therapy in anorexia nervosa. A 5 year follow-up. Arch Gen Psychiatry \\ 1997 Nov;54:1025-30.
}

\section{Question}

Compared with individual supportive therapy, can family therapy for 1 year improve the outcome at 5 years for patients who have been treated in hospital for anorexia nervosa and bulimia nervosa?

\section{Design}

Randomised controlled trial with 5 years follow up.

\section{Setting}

A hospital eating disorders unit in London, UK.

\section{Patients}

80 patients (age range 14 to $55 \mathrm{y}$ ) who had anorexia nervosa $(n=57)$ or bulimia nervosa $(n=23)$ and were discharged from hospital after treatment. Patients were classified into 4 groups according to the features of their illness: early onset $(\leqslant 18$ years of age) and short history ( $<3$ years) of anorexia nervosa; early onset and long history ( $\geqslant 3$ years) of anorexia nervosa; late onset of anorexia nervosa ( $>18$ years of age); and bulimia nervosa. Follow up was $91 \%$.

\section{Intervention}

Patients in each group were allocated to individual or family therapy: 11 and 10 patients for early onset and short history of anorexia nervosa; 9 and 10 patients for early onset and long history of anorexia nervosa; 7 and 7 patients for late onset of anorexia nervosa; and 10 and 9 patients for bulimia nervosa.

\section{Main outcome measure}

A good outcome was defined as having a body weight within $15 \%$ of the average body weight and regular menstrual cycles.

\begin{abstract}
Main results
In patients who had early onset and a short history of anorexia nervosa, those who received family therapy were more likely than those who received individual therapy to have a good outcome at 5 years $(p \leqslant 0.02)$ (table). In patients with late onset anorexia, a non-significant trend towards a better outcome at 5 years existed for patients who received individual therapy compared with those who received family therapy ( $57 \%$ v $29 \%)$. There were no differences between treatments for the number of good outcomes in patients who had bulimia nervosa or those with early onset and a long history of anorexia nervosa.
\end{abstract}

\section{Conclusion}

For patients with early onset and a short history of anorexia nervosa, family therapy led to more patients having good outcomes (body weight within 15\% of average body weight and regular menstrual cycles) at 5 years than individual therapy.

Family $v$ individual therapy in patients with early onset and short history of anorexia nervosa

\begin{tabular}{lllll}
\hline Outcome at 5 years & Family & Individual & RBI $(95 \%$ CI $)$ & NNT (CI) \\
\hline Good outcome & $90 \%$ & $36 \%$ & $148 \%(23$ to 503) & 2 (2 to 8$)$
\end{tabular}

*Abbreviations defined in glossary; RBI, NNT, and CI calculated from data in article.

Source of funding: Medical Research Council of Great Britain.

For correspondence:Dr G F M Russell, Hayes Grove Priory Hospital, Prestons Road, Hayes, Kent BR2 7AS, UK. Fax +44 (0)1814625028.

\section{Commentary}

This study by Eisler et al expands on a critical investigation in the late 1980 s which examined the efficacy of 2 treatments for patients who have anorexia nervosa and bulimia nervosa. ${ }^{1}$ Family therapeutic techniques had not previously been subjected to rigorous scrutiny; the results of the original study were one of the first pieces of empirical evidence supporting the use of family therapy for these illnesses.

Briefly, the original study showed that family therapy was the preferred treatment after leaving hospital for patients with anorexia nervosa who were $\leqslant 18$ years of age and had a short duration of illness. For older patients, individual therapy led to a better outcome.

The current report with 5 years of follow up confirms that the observed im- provements have persisted. The overall recovery rate at 5 years is about one third of patients, with an additional one fifth partially recovered, and nearly $40 \%$ still quite ill. Although the news of better outcomes for family therapy in younger patients with early onset and a short history of anorexia nervosa is encouraging, the rates of serious illness at 5 years are of concern, as is the nearly $5 \%$ mortality rate.

For clinicians, the most important issue is the choice of treatment. It must be noted that the investigators do not recommend family or individual therapy as an initial outpatient treatment. These are recommendations for treatment after the patient has been nutritionally rehabilitated and has had weight restored. Clinicians who intend to do work of this nature should carefully review the descriptions of the treatments.

Finally, the authors correctly conclude that a less favourable outcome, which was associated with additional treatment, was likely a marker for more severe or treatment resistant illness. Given that chronicity may be a marker for treatment resistance, ${ }^{2}$ clinicians must provide patients with anorexia nervosa with the best possible treatment as early as possible in the course of the illness.

Blake Woodside, MD, MSc, FRCPC University of Toronto Toronto, Ontario, Canada

1 Russell GFM, Szmukler GI, Dare C, et al. Arch Gen Psychiatry 1987;44:1047-56.

2 Theander S.J Psychiatr Res 1985;19:493-508. 